\title{
Nature of Noncovalent Carbon-Bonding Interactions Derived from Experimental Charge-DensityAnalysis
}

\section{Eduardo C. Escudero-Adán, Antonio Bauzffl, Antonio Frontera, and Pablo Ballester}

\author{
E. C. Escudero-Adán,+ Prof. P. Ballester \\ X-Ray Diffraction Unit \\ Institute of Chemical Research of Catalonia (ICIQ) Avgda. Països Catalans \\ 16, 43007 Tarragona (Spain) E-mail : pballester@iciq.es \\ A. Bauzffl,+ Prof. A. Frontera Department of Chemistry Universitat de les Illes Balears \\ Crta. de Valldemossa km 7.5, 07122 Palma de Mallorca (Spain) E-mail : \\ toni.frontera@uib.es \\ Prof. P. Ballester \\ Catalan Institution for Research and Advanced Studies (ICREA) Passeig Lluïs \\ Companys 23, 08010 Barcelona (Spain)
}

In an effort to better understand the nature of noncovalent carbon-bonding interactions, we undertook accurate high-res- olution X-ray diffraction analysis of single crystals of 1,1,2,2-tetracyanocyclopropane. We selected this compound to study the fundamental characteristics of carbon-bonding interactions, because it provides accessible s holes. The study required extremely accurate experimental diffraction data, because the in- teraction of interest is weak. The electron-density distribution around the carbon nuclei, as shown by the experimental maps of the electrophilic bowl defined by a $(\mathrm{CN}) 2 \mathrm{C}-\mathrm{C}(\mathrm{CN}) 2$ unit, was assigned as the origin of the interaction. This fact was also evidenced by plotting the D21(r) distribution. Taken together, the obtained results clearly indicate that noncovalent carbon bonding can be explained as an interaction between confront- ed oppositely polarized regions. The interaction is, thus elec- trophilic-nucleophilic (electrostatic) in nature and unambigu- ously considered as attractive.

Attractive intermolecular electrostatic interactions encompass electron-rich and electron-poor regions of two molecules that complement each other. ${ }^{[1]}$ Electron-rich entities are typically anions or lone-pair electrons and the most well-known elec- tron-poor entity is the hydrogen atom. Consequently, hydro- gen bonding is undoubtedly the most exploited supramolec- ular interaction. [2] Nowadays, another common electron-poor entity is attracting increasing attention in the literature. It is the 's hole', which can be defined as an electron-deficient anti- bonding orbital of a covalent bond. [3-13] Such regions of posi- tive electrostatic potential have been largely studied for atoms of groups V, VI, and VII (pnicogen, [14, $15]$ chalcogen, $[16-18]$ and hal- ogen ${ }^{[19-22]}$ bonding, respectively ${ }^{[23]}$ ). Many reviews have described halogen bonding in detail, which is the best-known s-hole interaction. ${ }^{6,19-22]}$ 
More recently, s-hole complexes with atoms of group IV, the tetrel ( $\mathrm{Tr}$ ) atoms, have been described, ${ }^{[24-29]}$ and mostly focus on the heavier Tr atoms as tetrel-bond donors, leaving noncovalent carbon bonding much less studied. ${ }^{[30-32]}$ In an $\mathrm{sp}^{3}$-hybridized electron-deficient $C$ atom, there is only limited space available for an electron-rich guest molecule to nest itself. ${ }^{[31,32]}$ To exem- plify this, we have represented in Figure 1 (right) the MEP sur-

Figure 1.

face of 1,1,2,2-tetracyanoethane (staggered conformation). The s hole is small and it is surrounded by negative belts, which hinder interactions with any concentration of negative charge (lone pair or anion). However, if the MEP surface is computed in the eclipsed conformation $(\mathrm{C} 2 \mathrm{v})$, the resulting $\mathrm{s}$ hole is more exposed and the electrostatic potential is considerable more positive. As a matter of fact, it has been recently demonstrated that the $(\mathrm{CN})_{2} \mathrm{C}-\mathrm{C}(\mathrm{CN})_{2}$ motif of 1,1,2,2-tetracyanocyclopropane is an excellent carbon-bond donor, because the $s$ hole is very exposed. ${ }^{[33]}$ Moreover, it is synthetically accessible and the $\mathrm{N}_{-} \mathrm{C}^{-}$is a poor leaving group, thus preventing the $S_{N} 2$ reaction. Therefore it is an ideal motif for studying noncovalent carbon bonding. Recently, it has also been demonstrated that fourmembered rings substituted with electron-deficient groups are also good s-hole donors. As a matter of fact, perfluorocubane has six s holes symmetrically distributed in the middle of six faces of the cube. Moreover, noncovalent carbon-bonding in- teractions have been found to be crucial to explain the solid-state architecture of nitrocubanes, where the $s$ holes are also very exposed. [34]

The aim of this Communication is to gain experimental in- sights into the nature of tetrel interactions in the solid state. Specifically, we focused our attention to noncovalent carbonbonding $(\mathrm{N} \cdots \mathrm{C})$ interactions. To achieve this, we carried out ac- curate high-resolution X-ray diffraction analysis of 1,1,2,2-tetra-cyanocyclopropane (1, see Figure 2). Compound 1 was selected to study the fundamental directionality characteristics of carbon-bonding interactions, because it is an excellent carbon- bond donor (see above). The properties derived from experiment and wave-function calculations for the multiple carbon- bonding interactions observed in a dimeric complex of 1 were analyzed and compared.

Figure2. 
Single crystals of two polymorphic forms (A and B) of 1 grew from ethanol solution (Figure 2). For one of them, we obtained high-quality experimental data that allowed reliable results on the experimental electron density to be derived. Atomic multipolar expansions[35, 36] were used to reconstruct the experimental electron density $1(r)$ of $1 \mathrm{~A}$ in the solid state. Dipole, quadrupole, and octupole moments were the most relevant terms to recover the experimental anisotropic $1(\mathrm{r})$ features of the crystal structure of $1 \mathrm{~A}$.

Figure 3 shows the static deformation of electron density obtained by subtracting a theoretical spherical model from the multipolar model $D 1(r)=1(r)$-1spherical $(r)$.

Figure 3.

The results of this topological analysis provide valuable in- formation on chemical bonding, which, in fact, enhances the value of such a multipole model. As the bond topological properties give a quantitative characterization of the strength of chemical bonds, [37] it is important to compare the properties derived from experiment and from wave functions. An immediate consequence of a bonding interaction is the existence of

a bond path between the involved atoms and the concomitant bond critical point (BCP) along this direction, where $1(r)$ exhibits a saddle topology. The observation of BCPs is, thus, distinctive of interatomic bonding interactions and the topological properties of $1(r)$ at the BCP permit characterization of the interaction. The examination of the crystal packing of 1 reveals the presence of multiple weak carbon-bonding interactions (see Figure 4) ranging from 3.02 to 3.17 Ç (8-3\% shorter than

Figure 4.

the sum of the vdW radii, 3.25 Ç)[38] in both polymorphs, thus confirming the theoretically predicted ability of this molecule to form noncovalent carbon-bonding interactions. We computed the lattice energy for both polymorphs by using a supercell of 16 molecules and periodic boundary conditions at the MP2[39]/def2-TZVP[40] level of theory (see the Supporting Information). The resulting lattice energies are similar, that is Elattice $=117.5$ and $118.7 \mathrm{~kJ} \mathrm{~mol}-1$ for $1 \mathrm{~A}$ and $1 \mathrm{~B}$, respectively ; where Elattice = Ecrystal $/ \mathrm{n}$-Emolecule.[41] In addition, the computed interaction energies of dimers of $1 \mathrm{~A}$ and $1 \mathrm{~B}$ represented in Figure 2 are -33.8 and $-36.4 \mathrm{~kJ} \mathrm{~mol}-1$, respectively, also at the MP2[39]/def2-TZVP[40] .

These binding energies are significant, taking into account the small basicity of the sphybridized nitrogen atom of the cyano group. To study whether orbital contributions are important to explain the noncovalent carbon interactions observed in the dimer of $1 \mathrm{~A}$, we performed natural bond orbital (NBO)[42] calculations at the MP2[39]/def2-TZVP[40] level of theory, focusing our attention on the second-order perturbation analysis.[43] It is useful to 
study donor-acceptor interactions.[44] Interestingly, we found that the lone pair of N1 interacts with both C1-C2 and C1-C3 (see Figure 2 for atom numbering) anti- bonding orbitals with a concomitant second-order stabilization energy of $1.42 \mathrm{~kJ}$ mol-1 for each interaction and the energetic difference between the $\mathrm{lp}$ and $\mathrm{s} *$ antibonding orbitals is 1.22 . Therefore, the stabilization energy that can be attributed to orbital effects $(2.84 \mathrm{~kJ} \mathrm{~mol}-1)$ is small compared with the total interaction energy $(-33.8 \mathrm{~kJ} \mathrm{~mol}-1)$ computed for this dimer. Consequently, this interaction is likely dominated by electro- static effects instead of orbital effects.

Using polymorph $1 \mathrm{~A}$, we computed the experimental (multi- pole refinement) and the theoretical (MP2[39]/def2-TZVP[40] wavefunction) distribution of BCPs and bond paths. The results for a selected trimer are shown in Figure 5.

Figure 5.

Four independent BCPs characterize the trimer. Remarkably, two are associated with the carbon-bonding interactions ( $c p 1$ and $\mathrm{cp} 2$ ). One of them connects the nitrogen atom with one sp3-hybridized carbon atom of the (CN)2C-C(CN)2 motif and the other one connects the nitrogen atom with the carbon atom of the $\mathrm{CH} 2$ group.

The magnitudes of both the electron density, $1(r)$, and the Laplacian $r^{2} 1(r)$ are shown in Table 1 and they fall within the

\begin{tabular}{|c|c|c|c|c|}
\hline & $1(r)$ & $\boldsymbol{r}^{2} 1(r)$ & $\begin{array}{l}\mathrm{G}(\mathrm{r}) \\
{\left[\mathrm{kJ} \mathrm{mol}^{-1}\right]}\end{array}$ & $\begin{array}{l}\mathrm{V}(\mathrm{r}) \\
{\left[\mathrm{kJ} \mathrm{mol}{ }^{-1}\right]}\end{array}$ \\
\hline $\mathrm{cp} 1(\mathrm{C} 1-\mathrm{N} 3)$ & $0.047(0.042)$ & $0.62(0.62)$ & $13.1(13.6)$ & $-9.4(-9.7)$ \\
\hline $\mathrm{cp} 2(\mathrm{C} 2-\mathrm{N} 1)$ & $0.066(0.062)$ & $0.88(0.94)$ & $19.4(21.0)$ & $-14.8(-16.5)$ \\
\hline cp3 (N2-N3) & $0.016(0.017)$ & $0.27(0.22)$ & $4.2(4.5)$ & $-2.6(-2.6)$ \\
\hline $\mathrm{cp} 4(\mathrm{~N} 1-\mathrm{N} 3)$ & $0.027(0.027)$ & $0.37(0.41)$ & $7.4(8.1)$ & $-4.9(-5.0)$ \\
\hline
\end{tabular}

range of hydrogen bonds. There is excellent agreement be- tween the theoretical and experimental distribution of BCPs, bond paths, and their topological properties, including local kinetic energy, $G(r)$, and the potential energy density, $V(r)$ (see Table 1 ). These energetic values

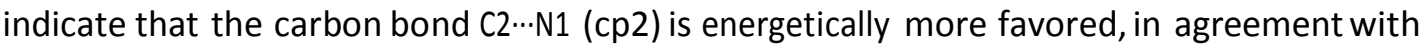


the MEP analysis. Interestingly the other s-hole-based carbon- bond interaction (cp1) is also energetically favored over the other two interactions characterized by cp3 and cp4).

Finally, we also obtained the theoretical and experimental molecular electrostatic potential surface (MEPS) for compound

1A. In Figure 6, we show the representation of both surfaces using two different electron density isovalues. In Figure $6 \mathrm{a}$ and Figure $6 \mathrm{~b}$, we show the MEPS representation using the van der Waals surface (isovalue for the electron density 0.001 a.u. according to Bader's definition). [37]

It can be observed that there is very good agreement be- tween both surfaces, including the blue region defining the shole. The experimental MEPS exhibits a lower potential energy value $\left(130 \mathrm{~kJ} \mathrm{~mol}^{-1}\right)$ than the theoretical one $\left(180 \mathrm{~kJ} \mathrm{~mol}^{-1}\right)$ at the $\mathrm{s}$ hole. This significant difference can be also considered as an experimental confirmation of the carbonbonding interaction. That is, the theoretical MEP is computed using the electronic density of an isolated molecule and the experimental one is obtained using the X-ray diffraction data, where the molecules are interacting with the neigh- boring ones in the crystal packing. In $1 \mathrm{~A}$, the $s$ hole of one molecule is interacting with the nitrogen atom of the adjacent molecule, thus receiving electron density from the nitrogen lone pair and reducing the positive potential at the $s$ hole. A a matter of fact, if the MEPS is computed using a smaller sur-face $(96.6 \%$ of the total electron density, isovalue $=0.01)$ in- stead of the vdW surface $(99.6 \%$, isovalue $=0.001$ a.u.), the experimental value at the $s$ hole significantly increases from 130 to 250 $\mathrm{kJ} \mathrm{mol}^{-1}$, because the influence of the lone pair of the adjacent molecule is reduced. The theoretical value at the $s$ hole also increases upon resizing the surface resulting in identical theoretical and experimental MEP values.

We report a combined experimental and calculated molecular orbital electron density study of $1 \mathrm{~A}$ accompanied with the corresponding accurate topological analyses to qualitatively characterize the noncovalent carbon bonding in $1 \mathrm{~A}$. The N...C intermolecular bond can be classified as a closed-shell interaction and its electrostatic nature is demonstrated by the mapped $\mathrm{D} 1(\mathrm{r})$ distribution for $1 \mathrm{~A}$. The interaction occurs be- tween a nucleophilic (or Lewis base) region $\left(d^{-}\right)$of a nitrogen atom and an electrophilic (or Lewis acid) region $\left(d^{+}\right)$of the carbon atoms in the $(\mathrm{CN})_{2} \mathrm{C}-\mathrm{C}(\mathrm{CN})_{2}$ motif of the three-membered ring in $1 \mathrm{~A}$. The region of positive electrostatic potential (s hole) is readily accessible making noncovalent 'carbon bonding' a viable supramolecular interaction between molecules of $1 \mathrm{~A}$ in the solid state. This finding is in sharp agreement with a recent thorough CSD analysis, ${ }^{[33]}$ providing strong support to carbon-bonding interactions in $(\mathrm{CN})_{2} \mathrm{C}-\mathrm{C}(\mathrm{CN})_{2}$ motifs. The interaction is highly directional in structures having $(\mathrm{CN}) \mathrm{CC}(\mathrm{CN})$ dihedral angles of $\mathrm{S} 158$. The experimental demonstration of the existence of a s hole in $1 \mathrm{~A}$ by means of the representation of the static deformation of the electron density isosurface is very relevant and gives reliability to the theoretically proposed existence of s-hole-based interactions involving carbon, the lighter tetrel atom 


\section{Experimental Section}

Single crystals of $1 \mathrm{~A}$ and $1 \mathrm{~B}$ were grown from a solution of 1 in ethanol heated at $458 \mathrm{C}$. High resolution X-ray diffraction data were obtained at $100 \mathrm{~K}$ on a Rigaku XtaLab P200 Mo Ka rotating anode equipped with a Pilatus $200 \mathrm{~K}$ detector (a hybrid pixel detector recommended for charge density studies). ${ }^{[45]}$ The multipolar $1(r)$ model was expanded up to the dipolar order $(I=1)$ for the $\mathrm{H}$ atoms and up to the octupolar order $(I=3)$ for the $\mathrm{C}$ and $\mathrm{N}$ atoms, applying the corresponding geometrical constrains using the pro-gram MOPRO. $[35,36,46]$ Optimization of the used restrains based on free R factors $[47]$ was performed. CCDC 1062475 and 1062476 contain the supplementary crystallographic data for this paper. These data are provided free of charge by The Cambridge Crystallograph- ic Data Centre.

\section{Acknowledgements}

The authors thank Ministerio de Econompa y Competitividad (MINECO) of Spain (projects CONSOLIDER INGENIO 2010 CSD2010-00065, Severo Ochoa Excellence Accreditation 2014-2018 SEV-2013-0319, CTQ2014-57393-C2-1-P and CTQ2014-56295-R), FEDER funds and the ICIQ Foundation for financial sup- port. We also thank Mr. Albano Galffln for providing a sample of 1.

Keywords: ab initio calculations ' charge density 'noncovalent carbon bonding . supramolecular chemistry $\mathrm{s}$ - hole interactions.

[1] Intermolecular Interactions: Physical Picture, Computational Methods and

Model Potentials (Ed.: I. G. Kaplan), John Wiley \& Sons Ltd., Chichester, 2006.

[2] Hydrogen Bonding - New Insights (Ed.: S. Grabowski), Springer Nether- lands, Dordrecht, 2006.

[3] A. C. Legon, Phys. Chem. Chem. Phys. 2010, 12, 7736-7747.

[4] M. R. Scholfield, C. M. Vander Zanden, M. Carter, P. S. Ho, Protein Sci. 2013, 22, 139-152.

[5] M. Erdflyi, Chem. Soc. Rev. 2012, 41, 3547-3557.

[6] E. Parisini, P. Metrangolo, T. Pilati, G. Resnati, G. Terraneo, Chem. Soc. Rev. 2011, 40, 2267-2278.

[7] J. S. Murray, P. Lane, T. Clark, P. Politzer, J. Mol. Model. 2007, 13, 1033-1038.

[8] T. Clark, M. Hennemann, J. S. Murray, P. Politzer, J. Mol. Model. 2007, 13, 291-296.

[9] J. S. Murray, P. Lane, P. Politzer, Int. J. Quantum Chem. 2007, 107, 2286-2292. 
[10] T. Clark, Wires Comput. Mol. Sci. 2013, 3, 13-20.

[11] T. Clark, P. Politzer, J. S. Murray, Wires Comput. Mol. Sci. 2015, 5, 169-177.

[12] J. S. Murray, P. Politzer, Wires Comput. Mol. Sci. 2011, 1, 153-163.

[13] P. Politzer, J. S. Murray, T. Clark, Phys. Chem. Chem. Phys. 2013, 15, 11178-11189.

[14] M. R. Sundberg, R. Uggla, C. Vinas, F. Teixidor, S. Paavola, R. Kivekas, Inorg. Chem. Commun. 2007, 10, 713-716.

[15] S. Scheiner, Acc. Chem. Res. 2013, 46, 280-288.

[16] P. Sanz, O. Mo, M. Yanez, Phys. Chem. Chem. Phys. 2003, 5, 2942-2947. [17] P. Sanz, M. Yanez, 0. Mo, New J. Chem. 2002, 26, 1747-1752.

[18] P. Sanz, M. Yanez, O. Mo, Chem. Eur. J. 2002, 8, 3999-4007.

[19] G. Cavallo, P. Metrangolo, T. Pilati, G. Resnati, M. Sansotera, G. Terraneo, Chem. Soc. Rev. 2010, 39, 3772-3783.

[20] P. Metrangolo, G. Resnati, Chem. Eur. J. 2001, 7, 2511-2519.

[21] K. E. Riley, J. S. Murray, J. Fanfrlik, J. Rezac, R. J. Sola, M. C. Concha, F. M. Ramos, P. Politzer, J. Mol. Model. 2013, 19, 4651-4659.

[22] S. J. Grabowski, Phys. Chem. Chem. Phys. 2013, 15, 7249-7259.

[23] P. Politzer, J. S. Murray, T. Clark, Phys. Chem. Chem. Phys. 2010, 12, 7748-7757.

[24] A. Bauzffl, T. J. Mooibroek, A. Frontera, Angew. Chem. Int. Ed. 2013, 52,

12317-12321; Angew. Chem. 2013, 125, 12543-12547.

[25] S. J. Grabowski, Phys. Chem. Chem. Phys. 2014, 16, 1824-1834.

[26] A. Bundhun, P. Ramasami, J. S. Murray, P. Politzer, J. Mol. Model. 2013, 19, 2739-2746.

[27] I. Alkorta, J. Elguero, A. Fruchier, D. J. Macquarrie, A. Virgili, J. Organo- met. Chem. 2001, 625, $148-153$

[28] I. Alkorta, I. Rozas, J. Elguero, J. Phys. Chem. A 2001, 105, 743-749.

[29] A. Bauzffl, R. Ramis, A. Frontera, Comput. Theor. Chem. 2014, 1038, 67-70.

[30] D. Mani, E. Arunan, Phys. Chem. Chem. Phys. 2013, 15, 14377-14383.

[31] S. P. Thomas, M. S. Pavan, T. N. G. Row, Chem. Commun. 2014, 50, 49-51.

[32] A. Bauzffl, T. J. Mooibroek, A. Frontera, Chem. Commun. 2014, 50, 12626-12629.

[33] A. Bauzffl, T. J. Mooibroek, A. Frontera, Chem. Eur. J. 2014, 20, 10245-10248. 
[34] A. Bauzffl, T. J. Mooibroek, A. Frontera, Phys. Chem. Chem. Phys. 2014, 16, 19192-19197.

[35] B. Guillot, L. Viry, R. Guillot, C. Lecomte, C. Jelsch, J. Appl. Crystallogr. 2001, 34, 214-223.

[36] C. Jelsch, B. Guillot, A. Lagoutte, C. Lecomte, J. Appl. Crystallogr. 2005, 38, 38-54.

[37] R. F. W. Bader, Atoms in Molecules-a Quantum Theory, Univ. Press, Oxford, 1990.

[38] A. Bondi, J. Phys. Chem. 1964, 68, 441.

[39] C. Møller, M. S. Plesset, Phys Rev. 1934, 46, 618.

[40] F. Weigend, R. Ahlrichs, Phys. Chem. Chem. Phys. 2005, 7, 3297-3305. [41] W. F. Perger, R. Pandey, M. A. Blanco, J. J. Zhao, Chem. Phys. Lett. 2004, 388, 175-180.

[42] A. E. Reed, L. A. Curtiss, F. Weinhold, Chem. Rev. 1988, 88, 899-926.

[43] F. Weinhold, C. R. Landis, Discovering Chemistry with Natural Bond Orbi- tals, John Wiley \& Sons, New Jersey, 2012.

[44] E. D. Glendening, C. R. Landis, F. Weinhold, Wires Comput. Mol. Sci.

$2012,2,1-42$.

[45] D. Stalke, Acta Crystallogr. Sect. B 2014, 70, 781-782.

[46] B. Zarychta, V. Pichon-Pesme, B. Guillot, C. Lecomte, C. Jelsch, Acta Crys- tallogr. Sect. A 2007, 63, $108-125$.

[47] A. Paul, M. Kubicki, A. Kubas, C. Jelsch, K. Fink, C. Lecomte, J. Phys. Chem. A 2011, 115, 1294112952. 



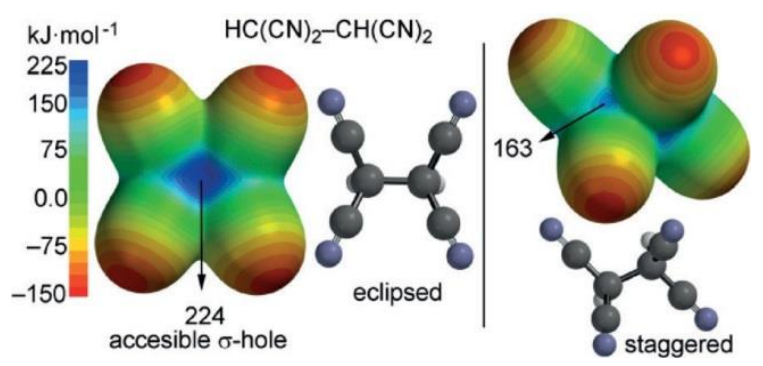

Figure 1. Electrostatic potential maps of 1,1,2,2-tetracyanoethane in the eclipsed (left) and staggered (right) conformations. Selected potential ener- gies at the $s$ holes are indicated. Energies in $\mathrm{kcal} \mathrm{mol}^{-1}$.
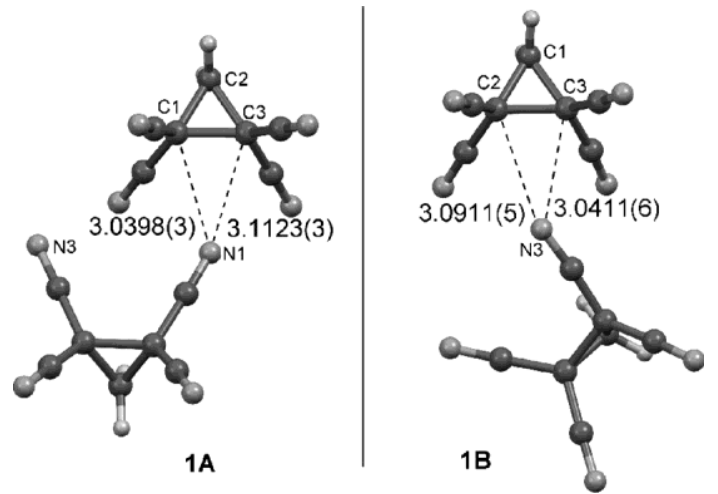

Figure 2. X-ray structures of the dimers present in the two polymorphic forms of 1. 


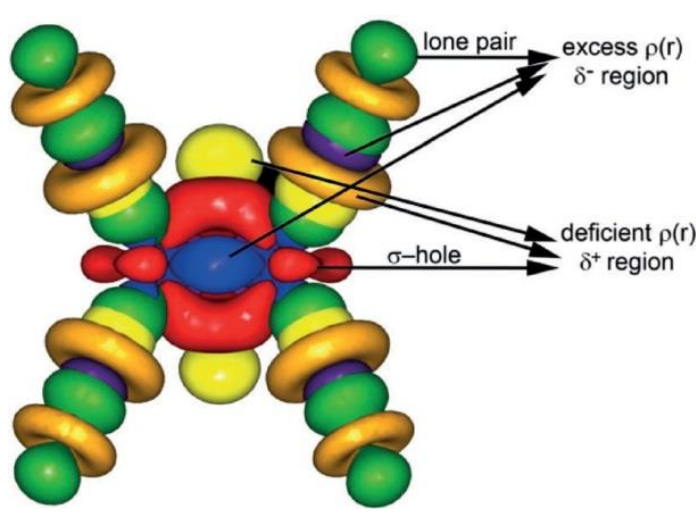

Figure 3. Map of $D 1(r)$ for $1 A$. The $D 1(r)$ isosurfaces are drawn at $\pm 0.1 \mathrm{eç}$. Electron-rich $\left(d^{-}\right)$and electron-deficient $\left(\mathrm{d}^{+}\right)$regions of octupole, quadru- pole, and dipole terms are color coded: blue and red for the octupoles, green and orange for the quadrupoles, and violet and yellow for the dipoles.

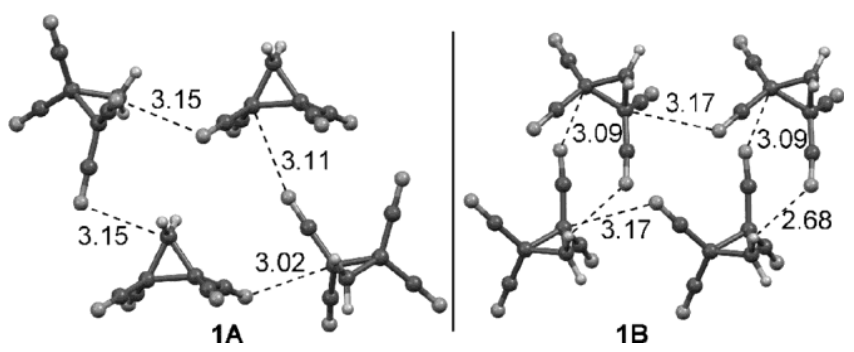

Figure 4. Carbon-bonding networks observed in the solid-state structure of 1 . The intermolecular $\mathrm{N} \cdots \mathrm{C}$ distances listed are in Ç. 


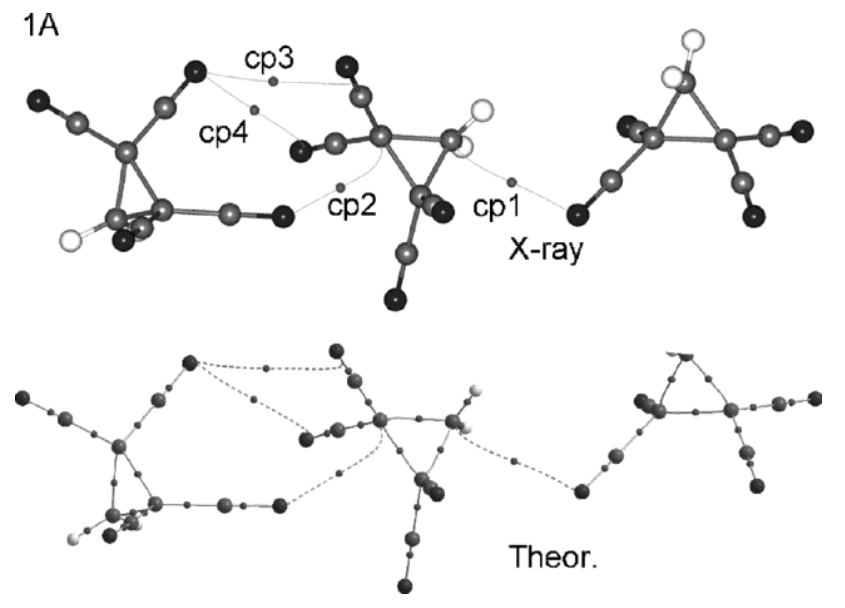

Figure 5. AIM distribution of critical points and bond paths in a selected trimer retrieved from the solid state-structure of $1 \mathrm{~A}$.

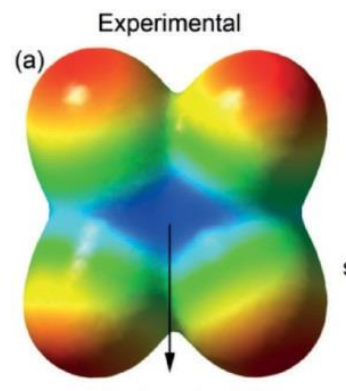

(c)

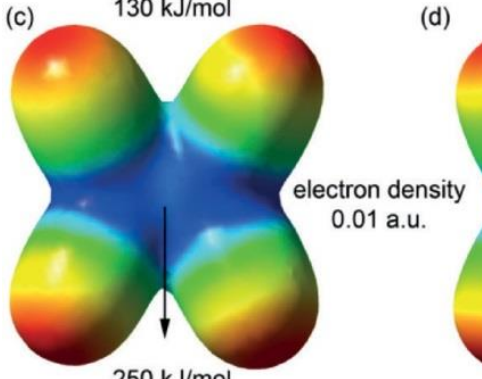

$250 \mathrm{~kJ} / \mathrm{mol}$ (b)

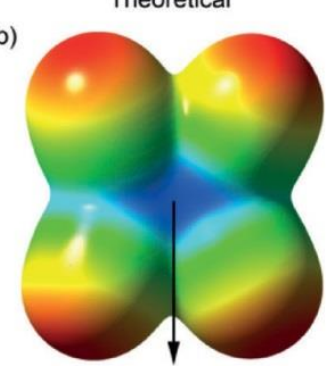

(d)

$180 \mathrm{~kJ} / \mathrm{mol}$

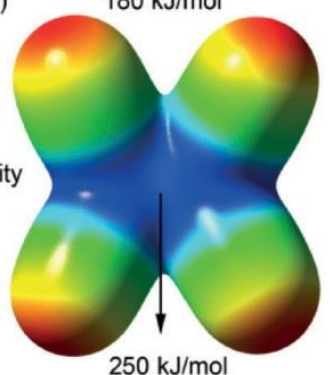

$250 \mathrm{~kJ} / \mathrm{mol}$

Figure 6. Experimental ( $a$ and $c$ ) and theoretical ( $b$ and $d)$ molecular electrostatic potential (MEP) surfaces calculated for $1 \mathrm{~A}$. For each surface, the red color represents the more negative energy potential value (located at the lone pairs of the $\mathrm{N}$ atoms) and the dark blue color corresponds to the high- est positive potential value (located at the carbon atoms). The VdW surface (a and b) corresponds to a density isovalue of 0.001 a.u. (1 a.u. $=6.748$ eÇ3). The surface for $\mathrm{c}$ and $\mathrm{d}$ relates to a density isovalue of $0.01 \mathrm{a}$.u. 